Ligia Giovanella 1

Luisa Guimarães 1

1 Escola Nacional de Saúde Pública Sergio Arouca,

Fundação Oswaldo Cruz, Rio de Janeiro, Brasil.

Correspondência

L. Giovanella

Departamento de

Administração e

Planejamento em Saúde,

Escola Nacional de Saúde

Pública Sergio Arouca,

Fundação Oswaldo Cruz.

Av. Brasil 4036, sala 1001

Rio de Janeiro, $R J$

21040-361, Brasil.

giovanel@ensp.fiocruz.br

\section{União Européia e MERCOSUL: mercados ampliados, soberanias desafiadas. Entrevista com Sonia de Camargo}

\author{
European Union and MERCOSUR: expanded \\ markets, challenged sovereignties. Interview \\ with Sonia de Camargo
}

Cientista política, com mestrado pela Faculdade Latino-americana de Ciências Sociais (FLACSO, Chile), doutorado pela Universidade de São Paulo e pós-doutorado pela Associação de Investigação e Especialização em Temas Ibero-americanos (AIETI, Espanha), Sonia de Camargo dirigiu de 1992 a 2004 o Instituto de Relações Internacionais do Centro de Ciências Sociais da Pontifícia Universidade Católica do Rio de Janeiro (PUC-Rio de Janeiro), onde é professora há quase três décadas.

Sonia de Camargo tem se dedicado desde meados dos anos 1980 ao estudo da integração regional entre países no contexto europeu e latinoamericano. Bolsista de Produtividade em Pesquisa do Conselho Nacional de Desenvolvimento Científico e Tecnológico (CNPq), trabalha em linhas de pesquisa sobre processos de globalização e integração regional, construção institucional da Comunidade Européia, questões institucionais e sociais na União Européia (UE) e no Mercado Comum do Sul (MERCOSUL), e processos de integração na América Latina.

Atualmente desenvolve pesquisa que visa a examinar o projeto de uma "nova Europa" por meio do estudo das diferentes posições, propostas e políticas para a UE em um momento de inflexão em sua trajetória político-institucional (com sua constitucionalização) e, de alargamento de seu espaço geopolítico com incorporação de Estados da Europa Central e do Leste. Seu interesse em prosseguir com essa temática se sustenta nos desafios postos para os atores e agentes envolvidos no processo e para aqueles que se propõem a compreendê-lo, dado o compromisso assumido pela UE de abrigar em seu espaço econômico e político-institucional novos Estados com diferentes trajetórias políticas, distintas culturas, costumes e línguas. Nesse contexto, as decisões a serem tomadas pelo conjunto de Estados e de cidadãos da UE constituem opções difíceis, ancoradas em valores, crenças, ideologias, interesses e visões de mundo múltiplas e nem sempre convergentes, que instigam a pesquisadora a desvendar estes processos para aprender lições e iluminar possíveis caminhos de integração com maior justiça social em nossa região. 


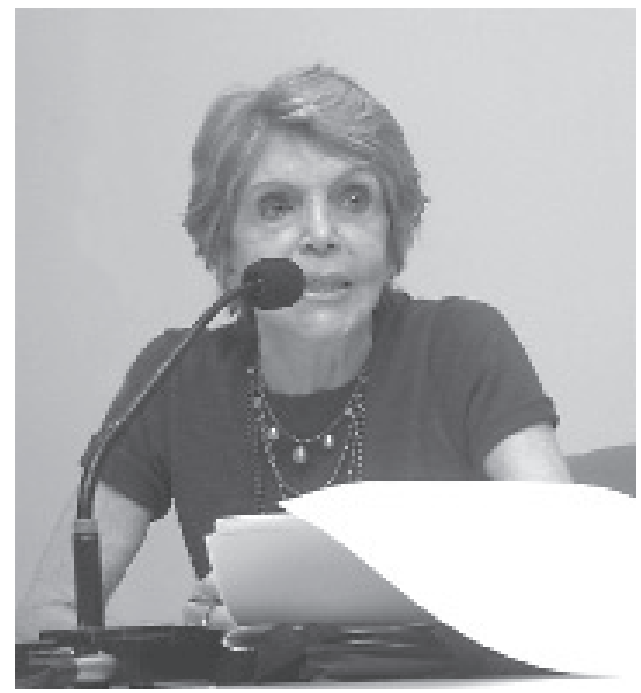

Profa. Sonia de Camargo durante o Foro MERCOSUR sobre Integración Regional y Sistemas de Salud, Rio de Janeiro, Brasil, março de 2006.

(foto: Gutemberg Brito).
Em entrevista a Ligia Giovanella e Luisa Guimarães, a pesquisadora Sonia de Camargo faz aqui uma série de reflexões sobre a UE e o MERCOSUL, partindo da idéia de que economias integradas ao mesmo tempo pressupõem e condicionam mudanças nas estruturas político-institucionais nacionais e regionais, bem como nas decisões e práticas políticas que as sustentam.

Para a pesquisadora, é essencial pensar politicamente os dois processos de integração - europeu e do MERCOSUL -, que se movem essencialmente na esfera econômica, mas exigem, além de uma moldura institucional que lhes dê impulso, legitimidade e operacionalidade, atores sociais capazes de gerar consensos, complementaridades e instrumentos de decisão em nível regional.
Giovanella \& Guimarães Num momento em que o MERCOSUL enfrenta obstáculos para atingir algumas de suas metas, observadores os comparam com as imensas dificuldades que também foram enfrentadas, e superadas, para que a UE se concretizasse. Existem pontos de convergência e similitudes entre os dois processos?

Camargo A UE, com uma precedência de mais de cinqüenta anos, atingiu, neste século, algumas metas que parecem estar cada vez mais longe do horizonte do MERCOSUL. É preciso levar em conta que as conjunturas nacionais, regionais e internacionais que presidiram o nascimento de cada um desses processos e seus principais determinantes estruturais, têm entre si mais diferenças do que semelhanças, indicando a necessidade de uma análise específica e particularizada de cada um deles.

Mesmo assim salientaria que, apesar das grandes diferenças entre os dois processos, o fato de ambos terem, entre seus objetivos finais, o de se tornarem mercados comuns e espaços políticos coordenados integradamente, nos permite encontrar entre eles pontos de convergência e de similitude. Esses pontos estão ligados ao fato de que mercados comuns implicam, necessariamente, o exercício de quatro liberdades fundamentais, a de pessoas, serviços, capitais e bens, situação que exige a constituição de regras, nor- mas e instituições de caráter intergovernamental ou supranacional que definam deveres, direitos e benefícios, assegurando que estes sejam distribuídos de forma previsível e eqüitativa entre todos os Estados-membros e setores sociais integrados ao projeto.

Essa questão se torna particularmente importante na atual conjuntura econômica mundial em que o sistema de acumulação capitalista, transnacionalizado e globalizado, tende a intensificar a iniciativa dos interesses privados com o decorrente enfraquecimento do poder de gestão interna dos Estados nacionais e de suas relações externas regionais e internacionais. Nesse contexto, os processos de integração entre Estados de uma mesma região funcionam como uma forma de regulação das relações econômicas e políticas entre eles e das transações entre agentes e atores que, mesmo tendo suas origens ancoradas no espaço nacional, ampliam seus horizontes, incorporando perspectivas, lealdades, formas de ação políticas compatíveis com a de seus parceiros regionais. Dessa maneira, por meio de um conjunto de instituições normativas e regras de atuação coordenadas intergovernamentalmente ou supranacionalmente, esses processos estabelecem uma forma de governança transnacional, em âmbito regional, colocando-se acima de uma pura anarquia e abaixo de um poder globalmente centralizado 1 . 
Tanto a UE quanto o MERCOSUL nasceram de um acordo entre os dois maiores países de suas respectivas regiões - França e Alemanha, no caso europeu, Brasil e Argentina, na América do Sul - não tardando que outros países fossem incorporados, Bélgica, Holanda, Luxemburgo, Itália, no primeiro caso, Uruguai e Paraguai, no segundo. Contudo, sua motivação inicial teve condicionamentos diferentes, especialmente no que se refere às questões de segurança, uma vez que a Europa ocidental, ainda convalescente das seqüelas de duas Guerras Mundiais tinha urgência, diferentemente da região sul-americana, de encontrar fórmulas e mecanismos que impedissem sua repetição e permitissem retomar, em algum ponto, o caminho interrompido. A Declaração Monnet-Shuman, de maio de 1950, representou uma resposta a esse apelo ao formular uma proposta de constituição de uma Federação Européia, cujos alicerces deveriam se apoiar numa nova relação entre França e Alemanha, assim como entre outros países europeus ocidentais que se mostrassem interessados. A decisão que se seguiu foi imediata: o estabelecimento de uma Comunidade que colocasse as indústrias de carvão e aço da Alemanha e da França sob uma mesma autoridade, com poderes e responsabilidades supranacionais nesses setores específicos. Dessa maneira, a constituição da Comunidade Européia do Carvão e do Aço (CECA) foi a fórmula encontrada para, mediante a incorporação da Alemanha em um projeto conjunto de integração produtiva, solucionar um dos problemas mais espinhosos da política externa da França, assegurando, ao mesmo tempo, a paz no continente e a recuperação econômica da região 2 .

É bem verdade que Argentina e Brasil também têm, como Alemanha e França, um passado de hostilidades e conflitos, porém não de guerras da dimensão das de 1914-1918 e 1938-1945. Grande parte desses conflitos se localizaram na Bacia do Prata onde, inicialmente, no período colonial, as coroas espanhola e portuguesa e posteriormente, os governos argentino e brasileiro, já independentes, disputaram, por quase dois séculos, o domínio da região. Esses conflitos, que implicavam o controle político dos dois países menores, Uruguai e Paraguai, se prolongaram durante todo o século XIX e entraram de forma subjacente no século XX até o momento em que, na metade do século, interesses econômicos compartilhados, ou melhor, projetos convergentes de desenvolvimento, abriram perspectivas conjuntas para os dois países e para a região sul-americana como um todo ${ }^{3}$.

A América Latina de fim dos anos 1950 e começo dos 1960 dá início a um processo de desenvolvimento integrado da região que, sob a orientação teórica da Comissão Econômica para América Latina e Caribe (CEPAL), visava ao seu crescimento econômico que se apoiaria em uma política de substituição de importações destinadas à formação de um parque industrial internacionalmente competitivo. Concretamente, o projeto propunha a formação de um mercado comum continental que deveria começar pela constituição de uma zona de livre comércio (Aliança Latino-Americana de Livre Comércio ALALC), formalmente estabelecida pelo Tratado de Montevidéu de 1960, prevendo-se a formação gradual de acordos sub-regionais nos marcos do projeto global.

G\&G A partir da segunda metade do século XX, a disputa pela hegemonia entre Brasil e Argentina evoluiu de que maneira? O movimento de aproximação entre os dois países avançou de uma forma consistente?

C A possível participação de Brasil e Argentina em um projeto sub-regional de integração foi adiada pela instauração, em ambos, de regimes militares que se prolongaram até o fim da primeira metade dos anos 80 . Contudo, em relação à região do Prata, onde a tradicional rivalidade tomara a forma de uma disputa em torno do aproveitamento energético dos rios por meio da construção de hidrelétricas, foi possível dar uma solução a essa disputa e assinar, depois de longas negociações diplomáticas, em 19 de outubro de 1979, um acordo entre Brasil, Argentina e Paraguai, o Acordo Multilateral Corpus-Itaipu, por meio do qual se formaliza a resolução de um conflito na esfera energética que parecia insolúvel.

Com isso se encerra um período em que a disputa pela hegemonia subcontinental cobrira a maior parte da história das relações bilaterais entre Argentina e Brasil, e se inicia outro em que a democratização de praticamente todos os países sul-americanos, entre os quais a Argentina e o Brasil, e maiores convergências políticas e econômicas abrem um espaço para novas fórmulas de cooperação bilateral e multilateral, cada vez mais condicionadas pelas novas tendências que, emergindo no plano internacional, obrigam os países sul-americanos a ajustarem suas políticas econômicas nacionais e regionais aos requerimentos da economia política global, cujas exigências de competitividade implicavam custos difíceis de serem administrados 3 .

Tanto a Comunidade Européia quanto o MERCOSUL se formaram a partir de um acordo bilateral entre os dois maiores países de cada região. Porém, no caso europeu, a Alemanha convalescia de uma grande derrota bélica sem, contudo, haver perdido sua histórica potencialidade de ressurgimento, o que marca uma diferença 
significativa na definição das prioridades estratégicas do acordo. Com efeito, dentro do contexto do pós-guerra, a proposta de cooperação França-Alemanha surgiu - além de suas óbvias motivações econômicas - como uma fórmula estratégica para neutralizar conflitos potenciais entre duas nações que, só neste século, se haviam confrontado militar e ideologicamente em duas guerras de alcance mundial e, paralelamente, para fortalecer a parte ocidental do continente em face das duas potências extra-regionais beneficiadas pela vitória, os Estados Unidos e a União Soviética. No caso do Acordo de Integração e Cooperação Argentina-Brasil, o entendimento só se deu depois que a possibilidade potencial de confronto entre os dois países já perdera força e sentido e não alimentava mais o imaginário dos novos governos democráticos que se propunham a encontrar formas de aproximação e cooperação política e convergências em um projeto de integração de seus mercados.

No plano econômico, ainda que as condições que conduziram alguns países europeus, nos anos 1950 e 1960, e países do Cone Sul latinoamericano, nos anos 1980 e 1990, a uma integração de suas economias fossem similares - uma vez que ambos os projetos foram pensados como maneira de responder a conjunturas econômicas extremamente negativas - as razões estruturais das dificuldades eram diferentes e portanto também o foram as modalidades de integração propostas, destinadas a reverter a precariedade das condições do continente destruído pelo conflito No caso europeu, após a opção pela criação de uma Comunidade que colocasse as indústrias de carvão e de aço da França e da Alemanha sob uma mesma autoridade, os passos seguintes foram dados pela incorporação da Itália e dos três países do BENELUX ao projeto de um mercado comum europeu, logo ampliado para a agricultura e o setor têxtil, medidas que desembocaram na assinatura, em Roma, em 1954, de um novo tratado que estabeleceu a Comunidade Econômica Européia.

No caso da integração bilateral ArgentinaBrasil, a conjuntura econômica internacional dos anos 1980 era, da mesma maneira, amplamente desfavorável à região. Mas, diferentemente da Europa, amplamente beneficiada por recursos externos provenientes do Plano Marshall, a América Latina não contou com os capitais e os mercados desses países no momento em que suas próprias economias perdiam dinamismo. No início dos anos 1980, o continente latino-americano, depois de quase duas décadas de um crescimento sustentado, sofre a pressão da crise econômica dos países centrais entrelaçada com a própria crise interna de suas economias nacionais.
O Brasil entra nos anos 1980 com um padrão de industrialização mais avançado de que seus vizinhos continentais, havendo incorporado à sua pauta de exportações, durante os anos 1970, bens semifaturados e alguns bens de capital, apesar de que este "crescimento em marcha forçada" custara ao país um altíssimo endividamento externo, obrigando-o a recorrer ao Fundo Monetário Internacional 4.

A Argentina caminha em sentido contrário. Com efeito, o modelo econômico posto em prática durante a segunda metade dos anos 1970, período governado por um novo regime militar, reviveu o velho projeto exportador primário da "geração de 1880", em que o eixo principal da acumulação se concentrava no setor agropecuário, no qual a Argentina tinha, tradicionalmente, vantagens comparativas no mercado mundial. Como fruto dessa política econômica, a matriz produtiva argentina sofreu uma verdadeira transformação. O país passou por um processo de desindustrialização em que os núcleos dinâmicos do setor manufatureiro foram intensamente sucateados 5 .

Essa era a situação econômica dos dois países que, na segunda metade dos anos 80, legitimados pelo processo de abertura democrática que ambos estavam vivendo, se propuseram a integrar regionalmente seus mercados como uma alternativa aos mercados dos países centrais que tendiam a se fechar. Em 1986 é constituído o Programa de Integração e Cooperação Bilateral Argentina-Brasil (PICAB), no marco do qual são assinados os primeiros Protocolos num total de 23 ao longo dos anos 86/88, dentre os quais o setor mais dinâmico foi o de bens de capital, essencial para a modernização e desenvolvimento científico-tecnológico do parque industrial nos dois países. Seguiu-se o estabelecimento de vários mecanismos de cooperação e, em 1988, é assinado o Tratado de Integração, Cooperação e Desenvolvimento e, dois anos depois, a Ata de Buenos Aires, por meio da qual se constitui o Grupo Mercado Comum, de natureza binacional. As negociações prosseguiram, já incluindo o Uruguai e o Paraguai e, em março de 1991 é assinado o Tratado Assunção, mediante o qual fica constituído o Mercado Comum do Sul, oficialmente chamado de MERCOSUL 6.

G\&G Como os europeus conseguiram avançar, em meio às dificuldades internas e externas, inclusive com a crise na economia mundial do final dos anos 1980?

C A Comunidade Européia de fins dos anos 80 prioriza o fortalecimento da esfera econômica, a única em relação à qual parecia haver consenso, deixando para trás objetivos mais claramente 
político-institucionais. O debate europeu passa a se concentrar em torno da formulação de um tratado que realizasse a constituição de uma UE, projeto que, redigido e aprovado pelo Parlamento Europeu em 1984, se propunha a ressuscitar a perspectiva federalista, gradualmente perdida em benefício do fortalecimento da perspectiva intergovernamental. A iniciativa não teve êxito, pois o tratado apresentado não foi ratificado pelos Parlamentos nacionais, com exceção do Parlamento italiano. Em seu lugar, foi aprovado, dois anos depois, o Ato Único Europeu, de alcance mais limitado no que se refere a mudanças institucionais substantivas, na medida em que, apoiando-se em uma racionalidade fundamentalmente econômica, se propunha apenas a reformar os tratados existentes, sem transformar sua natureza.

O objetivo de se aprovar um Tratado da União foi, assim, mais uma vez, adiado, e só foi concretizado em 1992 com a assinatura do Tratado de Maastricht que, apesar de não apresentar, tampouco, a radicalidade política do projeto de 1984, introduz reformas políticas e institucionais destinadas a facilitar a formação de um espaço sem fronteiras em que, não só a livre circulação de pessoas, capitais, serviços e mercadorias fosse assegurada, como a coesão entre as diversas regiões e grupos ficasse fortalecida e as próprias moedas nacionais - elementos mais visíveis, no plano econômico, da soberania nacional - fossem abolidas em benefício de uma moeda única para toda a região. Teve, assim, uma dupla função: por um lado a de incorporar a idéia antiga, generosa e um pouco vaga de União Política, que parecia esquecida, dando um contorno definido às Políticas Externa e de Segurança; por outro, a de absorver o projeto de União Econômica e Monetária que havia sido formulado nos anos oitenta por Jacques Delors, definindo os prazos e os passos para o estabelecimento de uma moeda e de um Banco Central únicos; medidas que deveriam resolver alguns dos principais impasses que perturbavam o andamento do processo ? Contudo, deixou de fora a proposta lançada pelo chanceler Kohl e pelo presidente Mitterrand, em 1990, de reunir a União Política à União Econômica e Monetária, o que abriria novamente a porta para o que fora a base das tentativas anteriores, uma combinação de aspectos econômicos e políticos marchando em um mesmo ritmo ${ }^{8}$.

Mas a tentativa do Tratado de Maastricht de conciliar posições diferentes e, muitas vezes, opostas, relativas ao caráter e às finalidades da unificação européia, não alcançou, no momento de sua aprovação, a receptividade esperada. Sua falta de precisão, preço pago para sua possível aceitação, que permitiu múltiplas leituras - des- de a vitória do eurofederalismo até sua derrota, desde o fortalecimento dos poderes da Comissão até sua limitação, desde a insuficiência até o excesso de competências dadas ao Parlamento - contribuiu para uma indecisão generalizada por parte dos eleitores europeus, que tinham mais dúvidas do que certezas sobre a natureza e significação reais do que lhes estava sendo oferecido. Por outro lado, não podemos nos esquecer que, às dificuldades internas, se somavam as dificuldades externas decorrentes das alterações do equilíbrio geopolítico do continente e da grave crise na economia mundial, cujos efeitos sobre a população dos países europeus ocidentais dificultavam suas opções 8 .

No momento em que o novo Tratado da União é apresentado à população européia, a tão falada "fortaleza européia" era invadida por acontecimentos que, trazidos do passado ou gerados no presente, irrompiam através de suas fronteiras, gerando indagações sobre a funcionalidade e o sentido do projeto assinado em Maastricht. $\mathrm{Ou}$ ainda, de forma mais radical, indagações sobre a pertinência de se continuar a pensar em um projeto que unificasse política e economicamente a Europa Ocidental, numa conjuntura em que não se sabia mais quais os limites territoriais que esse projeto iria abranger. No novo cenário pósGuerra Fria, coberto pela desintegração do antigo bloco do Leste e pela fragmentação da Europa Central, a queda do muro de Berlim transpôs para as margens da Comunidade Européia focos de conflito que tomaram a forma de lutas entre grupos religiosos, culturais, étnicos e diferentes formas de nacionalismo, revivendo a presença de velhos fantasmas como violência, miséria, discriminação, que os europeus acreditavam estivessem para sempre exorcizados. E também transpôs, para dentro de suas fronteiras, turbulências monetárias que puseram em questão a decisão de Maastricht de avançar de maneira irreversível na direção da união política e da criação de uma moeda única e de um Banco Central independente antes do fim do século. Contudo, apesar do pessimismo gerado pela paralisia política e pela recessão econômica, os países europeus ratificaram o Tratado da União, assinado em Maastricht. Essa aprovação demonstrou que, para a grande maioria dos europeus, se a UE se rompesse, o passado de lutas e conflitos no continente certamente voltaria com mais força, constituindo um dos grandes fracassos de sua história.

De qualquer maneira, dada a rapidez com que as transformações estavam ocorrendo no continente europeu dentro e fora das fronteiras da União, e dado o deslocamento destas fronteiras, que seriam alargadas pela absorção imediata de três novos Estados e, a mais longo prazo de 
mais dez, com outros muitos já na fila de espera, o Tratado de Maastricht previra, desde o início de suas negociações, uma avaliação, a curto prazo de seus objetivos, realizações e instrumentos normativos que administrassem as mudanças em curso. Paralelamente, a necessidade de se democratizar o modelo institucional comunitário e as práticas dele decorrentes ou, em outras palavras, de se criar as condições para que as autoridades de Bruxelas se aproximassem mais dos cidadãos, se apresentava como uma prioridade. Porém, a Conferência Intergovernamental que se realizou em março de 1996, por não demonstrar clareza sobre as perspectivas referentes à reforma das instituições e sobre a implantação definitiva de uma Política Externa e de Segurança comum, não produziu mudanças significativas nos aspectos que estavam em questão. Foi preciso esperar até 2004 para que a UE, já constituída de 25 Estados-membros, aprovasse no âmbito do Conselho Europeu reunido em Salônica, uma Constituição para Europa, a primeira, agora apresentada aos Estados e cidadãos europeus para sua aprovação, o que radicaliza a natureza supranacional de seu projeto de integração.

G\&G Que fatores, em sua opinião, fazem com que o MERCOSUL esteja ainda tão distante dos objetivos que nortearam o acordo entre Brasil e Argentina, que já completou duas décadas?

C O MERCOSUL está de alguma maneira estagnado, talvez mesmo em um momento de retrocesso, cada vez mais longe dos objetivos que haviam norteado o acordo de 1986. O início do processo de cooperação entre esses dois países se dera na forma da assinatura de 23 protocolos que abrangiam um conjunto variado de providências, entre as quais acordos de cooperação científicotecnológica e projetos setoriais integrados, como os de bens de capital, que marcavam a importância estratégica em termos de modernização industrial e de expansão do desenvolvimento técnico-científico dos dois países. Com a formação do MERCOSUL em 1991, esse paradigma é abandonado e se opta por uma nova metodologia traduzida na forma de um mecanismo linear, automático e universal de desgravação tarifária intra-regional. Com isso, se dá o deslocamento do eixo do acordo anterior e se adota um modelo essencialmente comercialista, vigente até hoje, deixando para trás a redefinição do padrão de industrialização dos países da sub-região e, conseqüentemente, do padrão de inserção de suas economias no mercado mundial ${ }^{9}$.

A conjuntura que o MERCOSUL está vivendo neste momento, em que conflitos comerciais no interior do bloco perturbam seu funcionamento gerando dúvidas sobre a funcionalidade do proje- to, sobre sua capacidade de gerar benefícios econômicos e políticos para seus Estados Membros e sua população, decorrem, justamente, do fato de que não dispõe de mecanismos efetivos de coordenação política que prevejam e previnam os conflitos. Na realidade, o MERCOSUL atual se debate, à deriva, em plena crise comercial, temendo que possa regredir a uma área de livre comércio regida por uma estrutura institucional que pouco tem avançado.

G\&G Nos anos 90, houve uma série de entraves econômicos, problemas internos e externos enfrentados pelos países da América Latina. Por exemplo, a mudança do sistema cambial no Brasil, em janeiro de 1999, teve grande impacto sobre os vizinhos. Qual a sua avaliação a respeito de pontos impactantes como esse? Pode-se pensar que a decisão brasileira repercute até hoje? C As dificuldades do MERCOSUL não podem ser imputadas exclusivamente a inconsistências internas ou erros em seu percurso. É preciso levar em conta a conjuntura internacional e a estrutura global da ordem mundial em cujo contexto foi constituído e que o acompanha em seu trajeto posterior diferentes da que presidira a criação e consolidação do Mercado Comum Europeu. O surgimento, nestas últimas décadas, de novos atores que disputam por melhores lugares no cenário econômico internacional e a inovação tecnológica que introduziu modificações na teoria clássica das vantagens comparativas, somados ao avanço da informática e das telecomunicações que gera um crescente fluxo de capitais desvinculados das operações comerciais, colocou para o MERCOSUL desafios cujas respostas exigem que seja incorporada à lógica comercial uma visão estratégica nos planos econômico, político e jurídico-institucional 10.

No que se refere às razões internas, os problemas são similares. A ausência de harmonização e de coordenação dos instrumentos de política econômica, próprias de etapas mais avançadas de integração, não permitiu que se garantissem condições eqüitativas de acesso ao mercado comunitário de produtos originários dos países incorporados ao acordo, dificultando sua posição competitiva e, como decorrência, fortalecendo a assimetria entre as economias da região.

Durante os anos 1990, a essas questões estruturais se juntaram dificuldades econômicas crescentes de seus países membros, derivadas da adoção de modelos de estabilização macroeconômica e de ajustamento estrutural às novas condições de comércio global que haviam adotado e de abertura indiscriminada de seus mercados. Mesmo assim, o MERCOSUL conseguiu eludir esses problemas por meio de acordos bi- 
laterais ou arranjos quadrilaterais que lhe permitiram avançar comercialmente em seu conjunto. Paralelamente em termos políticos, a idéia de democracia foi reforçada, uma vez que este princípio foi incluído no Protocolo de Ouro Preto, em 1994, tomando a forma de uma cláusula democrática regional lançada pelos governos brasileiro, argentino e uruguaio 11.

Mas ao chegar ao fim da década, o MERCOSUL começou a evidenciar pontos de estrangulamento que desafiavam a continuidade do processo. Um dos pontos de maior impacto foi a mudança do sistema cambial no Brasil com a decorrente desvalorização do Real, em janeiro de 1999, moeda que, desde 1994, mantivera a paridade fixa com o dólar, sistema adotado na Argentina desde 1991. A decisão do governo brasileiro, tomada unilateralmente e sem acordo prévio com os demais parceiros do bloco, rompia com a convergência anterior entre o sistema de câmbio fixo adotado nos dois países, o que não podia deixar de ter conseqüências sérias para a Argentina, dado seu alto grau de interdependência e de assimetria econômica em relação ao Brasil.

Nesse contexto, a Argentina, pressionada pelo desemprego e pela recessão, aprovou medidas de proteção contra qualquer produto importado dos membros do MERCOSUL, especificamente medidas de salvaguardas contra determinados produtos brasileiros, alegando que as regras do jogo haviam sido mudadas no meio da partida. As mudanças nas regras comerciais até então vigentes no MERCOSUL atingiram o Uruguai e o Paraguai, já fortemente integrados ao bloco, paralisando sua agenda negociadora e fazendo surgir propostas de abandonar os objetivos de uma integração produtiva entre os quatro países, e de volta a uma área de livre-comércio. Os conflitos recentes, especialmente entre Brasil e Argentina, em um contexto de inexistência de regras e instituições capazes de preveni-los e solucionálos, enfraquecem o projeto de mercado comum, gerando propostas que, em vez de ampliar suas competências, tendem a paralisá-lo ou mesmo a gerar um retrocesso.

G\&G Um aspecto fundamental dos processos de conformação de mercados comuns é a criação de novas institucionalidades supranacionais. Quais as principais diferenças entre UE e MERCOSUL no que se refere à questão institucional, à formulação e condução do processo de integração? Existem no MERCOSUL instrumentos e procedimentos que assegurem efetivamente a uniformidade e a coesão do processo?

C As questões colocadas até aqui são perpassadas pelo tema da institucionalidade que, por sua vez, se liga à natureza e aos objetivos de ca- da projeto. No longo trajeto da UE, a dicotomia entre uma "Europa de União de Estados" e uma "Europa super-Estado" constituiu o eixo em redor do qual se estabeleceram as prioridades e as esferas de competência. No momento em que aos cidadãos europeus é apresentada uma Constituição, que podem ou não aprovar, o que está em jogo, mais uma vez, é o lugar que ocupa, e as funções que exerce o Estado nacional dentro da União. Essa opção normativa se insere em um contexto em que a dimensão política e os diferentes interesses e crenças cognitivas no espaço europeu apostam em um ou em outro modelo institucional.

No MERCOSUL, preocupados com as disputas comerciais, especialmente entre Argentina e Brasil, o debate é outro. No caso da UE, a relação entre economia e política e entre intergovernabilidade e supranacionalidade foi relativamente bem resolvida por meio de combinações e formas de articulação variadas entre diferentes instâncias, níveis de atuação e competências. No MERCOSUL essas atividades são vistas como esferas isoladas de atuação, que não necessariamente caminham em um mesmo ritmo.

Nesse contexto, a percepção corrente em relação à qual se avalia o MERCOSUL é a de que a funcionalidade do bloco está ligada essencialmente à esfera comercial, mesmo que nesta área os ganhos comecem a ser fortemente questionados. Em termos econômicos gerais, o MERCOSUL não tem impulsionado um desenvolvimento significativo, dada a ausência de um projeto industrial para a sub-região e do pouco que se avançou no estabelecimento de um mercado comum. Mesmo assim, poderíamos pensar o MERCOSUL como um instrumento capaz de administrar e regular, em benefício de seus Estados-membros e de suas sociedades, o movimento global de transnacionalização financeira e de abertura dos mercados. Para isso ele deveria se constituir como uma força regional unificada, com poder de negociação no sistema internacional e de resistência às pressões vindas de Estados mais fortes, especificamente dos Estados Unidos, que pressionam para que seus países-membros sejam individualmente incorporados a suas áreas de influência e domínio. Como exemplo mais próximo podemos destacar as pressões feitas pelo governo norte-americano para que o Brasil e os demais Estados-membros do MERCOSUL se incorporem individualmente ao projeto de integração hemisférica (Área de Livre Comércio das Américas - ALCA), formulado e liderado pelos Estados Unidos. A posição conjunta dos países do MERCOSUL referente a essa questão e a outras que surgirem pode significar um meio de se fortalecer uma identidade regional ainda 
em formação e uma imagem internacional que tenda a adquirir contornos definidos.

Quanto à relação entre intergovernabilidade e supranacionalidade, este talvez seja um dos pontos em que o MERCOSUL mais se diferencie da UE, e que mais resistências tenha gerado no âmbito de seus governos, especialmente no do Brasil, em que a questão da supranacionalidade, mesmo limitada a certas competências específicas, é praticamente omitida no debate oficial. A pouca prioridade dada às questões institucionais na formulação e na condução do MERCOSUL tem a ver com o fato de que a dimensão política do projeto foi relegada a um segundo plano, discutindo-se pouco a criação de instrumentos e procedimentos que possam dar um marco de legitimidade e credibilidade ao processo, e que assegurem sua uniformidade e coesão.

Não há como escapar ao fato de que a passagem de mercados nacionais para um mercado único regional modifica a qualidade das relações entre os Estados Membros e entre suas sociedades, assim como o peso dos diferentes agentes produtivos e a localização de suas atividades. Essas alterações e deslocamentos trazem mudanças nas regras do jogo político entre os atores nacionais e os que já atuam nos planos regional e global, que exigem uma contínua revisão dos instrumentos institucionais de decisão, regulação e representação de que se pode dispor, podendo ser órgãos intergovernamentais ou supranacionais, dependendo da natureza do objetivo final que se quer alcançar e de sua eficácia e operacionalidade para esta realização.

G\&G Quais razões poderiam apontar para esta lentidão na criação de uma institucionalidade própria do MERCOSUL?

C Várias razões são apresentadas para explicar o fato de que a estrutura institucional do MERCOSUL tenha avançado com relativa lentidão. Dentre elas, saliento a posição dos meios diplomáticos brasileiros e de analistas e operadores de que as instituições do MERCOSUL são perfeitamente adequadas e funcionais à sua etapa atual, a de uma união aduaneira ainda imperfeita, ainda que, cada vez mais, sua Tarifa Externa comum esteja sendo perfurada em vários pontos. Ou a de outros setores da sociedade que, diante de uma possível radicalização do processo, em termos da supranacionalização de alguns de seus órgãos de decisão, dizem temer a perda de soberania nacional dos Estados incorporados ao acordo.

Esse argumento da perda de soberania me parece cada vez mais discutível. Na presente conjuntura mundial, essa perda não está ligada, especificamente, aos acordos regionais, mas à forma em que as empresas transnacionais, que agem livremente nos mercados globais, atropelam projetos e decisões formulados no âmbito dos Estados e/ou das regiões em processo de integração. Isso não nega o fato de que o estabelecimento de um mercado comum traz consigo cessão de soberania, ainda que possa ser parcial, o que não é necessariamente negativo.

O trajeto da UE avançou por meio de uma combinação pragmática entre esses dois termos e está agora em face de uma mudança radical, a de aprovar por referendo popular ou por via parlamentar, uma Constituição para toda a Europa. Com isso, esta nova Europa se propõe a ser uma Federação de Estados que prevê em aproximadamente dez anos novas adesões, que lhe permitirão cobrir um espaço com mais de trinta Estados Membros, entre os quais a Turquia, primeiro país muçulmano que se incorporaria à UE.

G\&G Como a senhora analisa a dimensão social nos dois processos de integração? Problemas sociais podem colocar em risco o que já foi obtido pela UE?

C De um modo geral a dimensão social é, dentre todas as formas de atividade nas sociedades capitalistas modernas, a mais controvertida e a menos resolvida. No mundo do trabalho, as ambigüidades e resistências às mudanças se acentuam, gerando profundas desigualdades. Se tomarmos como exemplo o cenário atual latinoamericano, no qual se inclui o MERCOSUL, constituído de quatro Estados Membros, e o cenário europeu, no qual se inclui a UE, constituída de 25 , vemos que ambos os processos se defrontam, em maior ou menor grau, com altas taxas de desemprego e exclusão, indicando-nos que o trabalho é a forma de atividade humana que está sofrendo com maior intensidade o impacto da transformação do paradigma produtivo-tecnológico e da organização da economia mundial contemporânea. O modelo fordista de produção que se apoiava em um determinado pacto social no qual o Estado tinha um papel central, entrou em crise pressionado pelas inovações tecnológicas dos últimos vinte anos, pelo enfraquecimento do Estado e do velho acordo social-democrata vigente, sobretudo, na Europa Ocidental 12.

A sociedade salarial, tendo perdido sua centralidade e havendo reduzido, graças às novas tecnologias que permitem separar produção e trabalho, sua participação do Produto Interno Bruto, está sendo gradualmente desregulada, flexibilizada, excluída na distribuição de bens econômicos, políticos e sociais, gerando uma pulverização do movimento dos trabalhadores organizados, que passaram a se aglutinar em torno de interesses corporativos ou individuais. 
Regionalmente, de um lado, "o social” se refere à própria legitimidade do processo, isto é, à sua aceitação por parte da pluralidade dos atores sociais - empresários, trabalhadores, população em geral - que passam a sentir que a integração é um assunto que lhes diz respeito e os compromete. Essa legitimidade será tanto maior quanto maior for sua capacidade para neutralizar os impactos negativos decorrentes do desenvolvimento do próprio processo. Outro aspecto tem a ver com a competência das instituições comunitárias para dar resposta aos problemas sociais, como desemprego, baixos salários, má distribuição de renda, precarização nos sistemas de saúde etc., não necessariamente decorrentes da integração em curso 13.

Mas a tarefa de se constituir um espaço social unificado em âmbito regional é duplamente difícil na medida em que as relações entre o Estado e "o social”, mesmo em âmbito nacional, são complexas e mal resolvidas. No caso dos mercados comuns como a UE e o MERCOSUL, realizações sociais efetivas exigem, como mínimo, a harmonização das legislações e das políticas sociais dos diferentes Estados-membros e de seus sistemas de proteção.

Os problemas sociais da UE se revestem, neste momento, de um caráter de urgência, na medida em que países centrais e do leste da Europa, com economias menos desenvolvidas, foram incorporados às suas fronteiras em $1^{\circ}$ de maio de 2004 e outros estão às suas portas, ao mesmo tempo em que levas populacionais de diferentes procedências, algumas já residentes na região, outras pretendendo fazê-lo, representam uma pressão crescente por condições melhores de vida. A UE está, assim, diante de uma encruzilhada que põe em perigo a legitimidade e a própria continuidade de tudo o que já foi construído. Essa preocupação não é nova, ela tem permeado toda a sua trajetória, em que avanços e recuos na questão social foram decorrentes das próprias determinações de cada conjuntura histórica. $\mathrm{O}$ que quero dizer é que a idéia de uma "Europa Social" esteve presente desde o Tratado de Roma de 1957 que já previra, em seus artigos 117 e 118, a necessidade de regulação do mercado de trabalho, uma vez que se alcançasse a livre circulação dos trabalhadores no espaço comunitário. A partir dessa lógica, foi criado um Fundo Social Europeu que, por meio de um programa de formação e aquisição de qualificações novas e de promoção do emprego destinado a melhorar as oportunidades para a população européia, propunha-se a elevar o nível de vida dos trabalhadores e sua mobilidade geográfica. Outra iniciativa foi a criação de um Comitê Econômico e Social constituído por representantes de empre- sários, trabalhadores, agricultores, profissionais liberais, consumidores e organizações familiares que, apesar de ter um caráter apenas consultivo deu, de alguma maneira, um enquadramento ao espaço social europeu.

Em 1987, o Ato Único Europeu, ao instituir o voto por maioria qualificada, marcou mais um avanço na área social ao conseguir que se aprovassem medidas relacionadas com a saúde e proteção dos trabalhadores. O processo desembocou, em 1989, na adoção - com exclusão da Grã Bretanha - de uma Carta dos Direitos Sociais Fundamentais dos Trabalhadores que abriu aos trabalhadores europeus o caminho para uma regulamentação mínima, concreta e juridicamente vinculante.

O passo seguinte foi dado pelo Tratado de Maastricht de 1992, que consagrou os princípios da "coesão econômico-social" e da "solidariedade", e ampliou as abrangências das questões a serem decididas pelo voto da maioria, incorporando a esta nova modalidade de decisão o tema das condições de trabalho e o direito dos trabalhadores à informação e consulta. Em 1997, o Tratado de Amsterdã consolidou as conquistas da fase anterior e definiu, como um de seus objetivos básicos, a questão do emprego e dos direitos dos cidadãos europeus. Paralelamente ficou decidido que o Protocolo Social, anteriormente rejeitado pelo governo britânico, fosse incorporado ao Tratado, cujos efeitos passaram a ser vinculantes para os então quinze Estados Membros. Contudo, poucas medidas foram previstas no sentido de avançar concretamente na construção de uma estrutura social comum, uma vez que a política de empregos e demais políticas sociais permaneceu, basicamente, na mão dos Estados- membros.

Ainda persistem grandes resistências à transferência do exercício das funções de gestão pública do nível nacional para o nível comunitário, tal como ocorrera em outras esferas, como a da Política Agrícola e Política Comercial Comuns. Uma iniciativa nesse sentido foi lançada em 21 de outubro de 1997, em Luxemburgo, quando os quinze países membros tomaram a decisão de adotar, ainda que em termos bastante minimalistas e, sobretudo, simbólicos, um programa de luta contra o desemprego: cada país foi obrigado a definir um plano nacional para criar condições de satisfazer alguns objetivos gerais, como apresentar novas propostas de emprego, assegurar uma formação ou ocupação a cada jovem antes de alcançar seis meses de desemprego e a cada adulto, antes de doze meses de inatividade.

G\&G Ou seja, as perspectivas nesse âmbito não podem ser classificadas de otimistas? 
C As perspectivas continuam pessimistas, pois sem a participação e pressão dos trabalhadores organizados dificilmente essas iniciativas darão resultado. O movimento sindical, preso à luta diária pela sobrevivência e pela conservação do emprego, tem perdido força, unidade e combatividade, nos países da UE e na maior parte do mundo. Soma-se a isso o fato de que os assim chamados "custos do trabalho" são apresentados como o principal obstáculo à competitividade das empresas nos mercados internacionais e como a causa essencial do próprio desemprego, o que conduz à adoção, pelos poderes públicos e forças privadas, de medidas de desregulamentação e flexibilização dos direitos trabalhistas, de precarização das condições de trabalho, de diferenciação dos salários, cada vez mais difíceis de serem revertidas.

Nesse contexto, os ganhos que a velha Comunidade Econômica Européia, apoiada nos princípios tradicionais da velha social democracia, se havia proposto atingir, mostraram-se difíceis de serem alcançados. Essas dificuldades se tornam maiores na atual conjuntura internacional em que o ciclo de acumulação do capital, ancorado em uma lógica essencialmente competitiva, exige requisitos que certamente a UE terá maiores problemas para cumprir. Na realidade, ainda que os resultados da aplicação de Fundos Regionais tenham sido satisfatórios nos últimos dez anos, no atual contexto em que a UE trouxe para dentro de suas fronteiras 100 milhões de novos habitantes de diferentes procedências e culturas, com níveis de desenvolvimento econômico significativamente mais baixo do que os dos países já membros da União, dificilmente políticas de nivelamento e de distribuição de recursos deixarão de gerar resistências por parte dos antigos membros que ainda dependem de benefícios e subsídios comunitários.

A reforma política que está sendo proposta pela UE, que inclui a aprovação de um Tratado ancorado em uma Constituição, é justamente uma tentativa de unificar as competências, poderes e decisões ao redor de questões básicas, entre as quais uma agenda econômica e social extensa e a consolidação de formas de representação popular que assegurem uma distribuição de bens políticos e econômicos eqüitativa entre toda a população. Contudo, o debate que a sociedade européia tem feito em redor da Constituição e, especialmente o voto negativo da França e da Holanda mostram, entre outras questões, que as políticas econômicas propostas, particularmente em sua versão social, isto é, aquela que atinge diretamente a moradia, o emprego, a saúde e educação, não geram confiança em boa parte da população européia. O temor embutido nos que disseram ou dirão "não" à Constituição é de que, no que se refere às questões econômicosociais, o documento é excessivamente liberal, isto é, dominado por uma lógica essencialmente financeira, construindo-se, portanto, como uma ameaça às conquistas social-democratas obtidas ao longo do tempo.

Sem querer examinar se a responsabilidade desse retrocesso pode ser imputada à Constituição ou à própria crise da social-democracia em face da vitória global do liberalismo, o fato é que a UE está diante de um impasse que terá de ser enfrentado com políticas sociais mais abrangentes e agressivas, em que novos mecanismos de solidariedade e de participação nos bens produzidos pela sociedade impeçam o naufrágio total do Estado de Bem-Estar, sem o qual a constituição de uma federação de Estados e de um grande mercado comum em dimensão continental se tornaria irrealizável.

G\&G E como as questões sociais estão sendo tratadas no âmbito do MERCOSUL?

C Grande parte das questões referentes à dimensão social não fazem parte da agenda do MERCOSUL, uma vez que o projeto de integração avançou pouco no que se havia proposto alcançar: um mercado comum para toda a sub-região, onde uma ampla circulação de pessoas, bens, serviços e capitais estaria assegurada. No Preâmbulo do Tratado de Assunção, faz-se uma menção apenas lateral a um desenvolvimento econômico com justiça social, demonstrando a predominância de uma lógica fundamentalmente econômica em que os ganhos sociais são percebidos como o resultado natural do próprio desenvolvimento produtivo, da modernização da economia e da ampliação dos serviços no espaço regional.

Mesmo assim, motivadas pela crescente liberalização dos fluxos de comércio e de capitais e pela abertura das economias, as Centrais Sindicais dos quatro países se mobilizaram, seja no âmbito de atuação dos respectivos Estados nacionais, seja no da Coordenadora das Centrais Sindicais do Cone Sul, e formaram uma Comissão Sindical voltada para o acompanhamento do MERCOSUL e para a procura de uma maior influência em seus rumos. É nesse espaço que se iniciou a discussão sobre a importância da luta pela ratificação dos convênios da Organização Internacional do Trabalho (OIT) e da formulação de uma Carta Social dos Direitos Fundamentais inspirada na Carta Social da UE. Essas medidas se destinavam a homogeneizar as condições mínimas de proteção ao trabalhador e a pressionar os governos e as entidades empresariais no sentido da busca de consolidação e ampliação de seus direitos e ganhos específicos. Contudo, dadas as 
dificuldades de aceitação por parte dos governos e dos empresários de uma Carta Social com conteúdos normativos amplos, os setores sindicais, representados no Subgrupo de Relações Trabalhistas, Emprego e Seguridade Social, de caráter tripartite - governo, empresários, trabalhadores - decidiram apresentar ao Grupo MERCOSUL, em novembro de 1997, uma proposta mais restrita de adoção de um Protocolo Sócio-Laboral que, na forma de um instrumento supranacional ou de direito privado ou de um Protocolo Adicional, deveria representar a consciência social do MERCOSUL.

Aqui, gostaria de ressaltar um ponto que merece reflexão. Apesar da ausência de políticas que, em nível regional, combatam a histórica desigualdade social dos países- membros do MERCOSUL e da assimetria entre eles, a criação, em 2004, de um organismo consultivo de representação da sociedade civil, o Fórum Consultivo Econômico e Social, com forte presença sindical e atuação combativa unificada, sugere uma mudança de cultura política do movimento sindical, ou ao menos de parte dele. Caberia a pergunta: estaríamos mesmo testemunhando a formação de uma consciência social coletiva no espaço MERCOSUL e talvez mesmo no espaço internacional? Outras perguntas seriam: como isso se daria num momento em que o mundo do trabalho é crescentemente exposto a todas as formas de penalidades, desde a "flexibilização" dos direitos trabalhistas até a eliminação de grande parte dos postos de trabalho, passando pela precarização do próprio trabalho? Como poderia ocorrer quando o próprio sindicalismo está fragilizado e a informalidade aparece como a alternativa mais viável?

G\&G Já há respostas para essas perguntas? Que resultados podem ser esperados da formação de uma consciência social coletiva no MERCOSUL? C As respostas não são fáceis, mas começam a aparecer nas várias iniciativas já apontadas e em outras que mostram que o próprio processo de integração, ao aproximar trabalhadores e organizações sindicais de diferentes países que enfrentam problemas similares, amplia suas fronteiras de luta, não só sobrepondo-se à clássica oposição entre nacional/regional/mundial, como incorpora novos temas à agenda da classe trabalhadora. Com efeito, se levarmos em conta a constante reivindicação do movimento sindical do MERCOSUL de participar em outros subgrupos de trabalho que não o especificamente dedicado às questões trabalhistas e de estar presente em foros institucionais como, além do Foro Consultivo Econômico e Social do MERCOSUL, da OIT e do Fórum dos Trabalhadores das Américas, vemos seu compromisso crescente em discutir questões gerais referentes ao processo de integração e em influir em sua condução.

É claro que os resultados são ainda incipientes, dadas as dificuldades apontadas para a formação de uma estrutura social unificada em âmbito regional, sobretudo levando-se em conta que é uma experiência nova para o movimento sindical sul-americano e que não recebe nenhum apoio dos respectivos governos que, de modo geral, consideram prematura a harmonização de leis e de políticas em âmbito regional, especialmente quando se trata de questões sociais. Por outro lado, ninguém desconhece as dificuldades em se harmonizar mercados de trabalho que apresentam fortes disparidades e grandes diferenças de comportamento e modos de funcionamento. A tarefa, portanto, de se constituir um espaço comum, no âmbito do MERCOSUL que implique convergências e solidariedades efetivas é, acima de tudo, dos próprios trabalhadores organizados, pois neste plano não se admitem soluções apenas administrativas e burocráticas. Ela exige a criação de situações reais de cooperação e de laços de integração transnacional efetivos, mesmo que a conjuntura econômica e ideológica atual, que tende a acirrar os conflitos e a exaltar a competição, não facilite o trajeto. 


\section{Referências}

1. Aragão JM. La harmonización de políticas en el MERCOSUR. La construcción de un mercado comun. Buenos Aires: Banco Interamericano de Desarrollo; 1993.

2. Camargo S. Europa Ocidental e América do Sul, duas regiões à procura de sua integração. Contexto Internacional 1993; 15:193-213.

3. Cervo AL, Bueno C. História da política exterior do Brasil. São Paulo: Editora Ática; 1992.

4. Barros-de-Castro A, Pires-de-Souza FE. A economia em marcha forçada. Rio de Janeiro: Editora Paz e Terra; 1985.

5. Camargo S, Vasques-Ocampo JM. Autoritarismo e democracia na Argentina e Brasil, uma década de política exterior (1973-1984). São Paulo: Editora Convívio; 1988.

6. Medeiros M. La genèse du MERCOSUL. Paris: L'Harmattan; 2000.

7. Quermonne JL. Trois lectures du Traité de Maastricht essay d'analyse comparative. Revue Française de Science Politique 1992; 42:802-18.

8. Muns J. Maastricht: las lecciones no aprendidas y los errores que no debieron cometerse. Revista CIDOB d'Affers Internacionales 1993; (25):25-36.
9. Veiga PM. A evolução do MERCOSUL no período de transição: hipóteses alternativas e cenários. Rio de Janeiro: Fundação Centro de Estudos do Comércio Exterior; 1992. (Texto para Discussão, 67).

10. Bernal-Meza R. Sistema mundial y MERCOSUR. Globalización, regionalismo y políticas externas comparadas. Buenos Aires: Universidad Nacional del Centro de Província de Buenos Aires/Grupo Editor Latinoamericano; 2000.

11. Vaz AC. Cooperação, integração, e processo negociador: a construção do MERCOSUL. Brasília: Editora Instituto Brasileiro de Relações Internacionais; 2002.

12. Camargo S. O institucional e o social em processos de integração: o caso da União Européia. Rio de Janeiro: Instituto de Relações Internacionais/ Pontifícia Universidade Católica do Rio de Janeiro; 1996. (IRI-Textos, 70).

13. Charrillon F. Union Européenne: une année laborieuse. Notes et Études Documentaires 1997; (5056-7):311-41.

Recebido em 23/Mai/2007

Versão final reapresentada em 25/Mai/2007 Aprovado em 25/Mai/2007 